\title{
Activated alumina preparation and characterization: The review on recent advancement
}

\author{
A. R. Rabia ${ }^{1}, A . H$. Ibrahim ${ }^{1 *}$, and N. N. Zulkepli ${ }^{2}$ \\ ${ }^{1}$ School of Environmental Engineering, Universiti Malaysia Perlis, Kompleks Pusat Pengajian Jejawi \\ 3, 02600 Arau, Perlis, Malaysia \\ ${ }^{2}$ Faculty of Engineering Technology, Kampus Uniciti Alam Sg. Chuchuh, 02100 Padang Besar, \\ Universiti Malaysia Perlis, Perlis, Malaysia
}

\begin{abstract}
Aluminum and aluminum based material are significant industrial materials synthesis because of their abandonment, low weight and high-quality corrosion resistance. The most advances in aluminum processing are the ability to synthesize it's under suitable chemical composition and conditions, a porous structure can be formed on the surface. Activated alumina particles (AAP) synthesized by the electrochemically process from aluminum have gained serious attention, inexpensive material that can be employed for water filtration due to its active surface. Thus, the paper present a review study based on recent progress and advances in synthesizing activated alumina, various techniques currently being used in preparing activated alumina and its characteristics are studied and summarized
\end{abstract}

\section{Introduction}

The level of heavy metals in drinking water is getting very high in both villages and cities due the activities such as mining and industrial waste disposal which will bring clean environment and sanitation [1]. Therefore, it becoming important physicochemical needed to be factor, which needed be considered when assessing water quality for both human, animal and plant consumption according to [1-3] this will enhance the condition of wellbeing animal and human. It is well known medically that heavy metal excess causes health problems to the human beings as stated by [2] which lead to several health problems such bladder blocking in order hard urinary track blockage etc [3]. The consumption of drinking water with a heavy causes prevailing health problem in the population, and the constant consumption of water containing heavy metals provokes serious high concern such as urine tract blockage and infection and equally problem that is associated with serious bone abnormalities and recently discovered problem as mentioned in [1-5]. The concentration of heavy metal and other impurities in water for human consumption may be reduced through the following methods: such as ion exchange on polymeric resins,

\footnotetext{
*Corresponding author: abdulhaqi@unimap.edu.my
} 
adsorption, reverse osmosis, and electro-dialysis which is illustrated in [3, 5]]. However, the most effective method proposed is the adsorption on activated alumina as clarify by [6]. Activated alumina is very available in sustainable quantity, which can be harness with little effort and is an inorganic porous material, semi-crystalline and essentially comprised by aluminum oxide that can be easily produce with high quality in reasonable amount as stated by $[1,5-10]$. The material shows amphoteric character that allows the material to behaves like a base in acidic solutions, and as an acid in basic solutions, which easily pre-treated for desired goal [6]. Moreover, it has be reported unwanted material such as heavy metals and other materials in water has been a major challenge and the pollution in the water is quite heavy today due to the release of toxic component from various sources; this has caused various health disorders. There are several attempts to treat or pollutant degradation and purifying various products such as water [7, 10].

According to [11] among these approaches are biological, chemical and bioelectrochemical dealt with chemical treatments this needing to consuming time and costly. However, adsorptive removal pollutant using different adsorbents is more promising and economical which could used in many applications [12-15]. Among various adsorbents used, activated alumina is well known for its high adsorption capacity due to large surface area and pore volume can be engineered and utilised in various application [1]. The water treatment technology via aluminum has gained a great importance in recent time competing with conventional technologies in various industrial fields in particular for chemical and petrochemical industries that material have shown capability to treat water long time in history and equally some other inorganic and organic such as phenol etc. which appeared in [12]. Currently, Aluminum play a special role in the field of energy and electric power as one of the elemental parts of conducting material due to availability and cheapness that material has gain a wider application, it has be use through the with help addition component such membrane, use in separation process technology [14]. Since the beginning of 1960's, aluminum was used as coagulant in local water purification. At the beginning of 1970 's, the first industrial installation of membrane using aluminum was initiated and using this platform, the water purification related activities rapidly grown and developed largescale commercial. With this initiative, it began to insert significant improvements in membrane selectivity / permeability and process design which could be used in many applications and processs [4]. The main goal of improving the membranes permeability is to achieve constant quality, high performance membrane and systems for desired applications with enhanced troubleshooting capabilities, which could be used in many applications and process [4].

There are several methods to treat heavy metals arsenic at household level; oxidation of As (III) can be done through chemical like bleaching powder and chemical such as potassium permanganate as stated in [2]. Unfortunately, the bleaching based powder are usually bring about an unpleasant taste in the treated water where in most cases, this material equally cause serious lung diseases moreover, these chemical are prone to cause discomfort by formation of methanes and methane related chemical species which could be used in many applications and processs [5].

Thus, is a very dangerous chemical to use for daily treatment of the house hold water and the quality of bleaching powder available in the open market of varies widely, it is very difficult to ensure the proper dosing of bleaching powder which could be used in many applications and processs [15]. On the other hand, potassium permanganate is a stable chemical and easily available locally to be used in industrial level or local level [17]. However, it produces a color in the treated water making it less attractive for drinking [18]. If the problem of color can be solved, potassium permanganate is preferable as an oxidizing agent, which could be used in many applications and processs [3]. 


\section{Activated Alumina}

Activated alumina is a high-surface-area, highly porous form of aluminium oxide which recently attracted the attention of various researchers [19]. It can absorb gases and liquids without changing its form. It works as a desiccant through adsorption and other impurities such as in water or other product; it gives clean water due to ability to attract impurities [12]. As water passes through the alumina, the polluted in the water sticks it and becomes trapped and water that passes through an activated alumina filter out [17]. Activated alumina is materials, which utilizes the principle of adsorption to prevent environmental pollution and can be regenerated merely burning it with high temperature between 300 to $400^{\circ} \mathrm{C}$ [18]. It has been used for recently in industrials as adsorbent to remove impurities from gaseous or liquids and to polish effluent for meeting stringent discharge standard; as catalyst to improve process efficiency; and as gases container to store pure gas and other product. The adsorption performance of alumna is determined by available surface area for physisorption and available adsorption site for chemisorption. Many researches had studied on methods for alumina regeneration due to the fact that regeneration is cheaper than replacement [20]. Furthermore, regeneration and reuse of alumina is also a practical way to reduce secondary pollution and conserve natural resources [19]. Generally, activated alumina behaves in much way like activated coal, which is a familiar adsorbent. The adsorption process depends on the force field that exists at the surface of a solid. Activated alumina possesses several uniqueness such as high adsorption capacity, high surface area, wide spectrum of functional group and variety of porosity sizes which made it suitable to be applied for the treatment of wastewater treatment plant effluent throughout the world $[22,23]$.

It has been reported by [23] that the activated alumina was used in wastewater treatment plant and they claimed that its can be used to reduce the concentration of heavy metal in the wastewater effluent for the compliment of Malaysian regulation of Environmental Quality (Industrial Effluent) Regulations 2009 for permissible discharge levels [3] There are many research of heavy metals adsorption using the activated. Normally activated alumina is used for adsorption since activated alumina has a wide variety of target pollutants such as organic pollutant, dyes and even heavy [19]. According to [23]. The Inhibitory effects of phenol compound on microbial activity have been reported for concentrations larger than $500 \mathrm{ppm}$ [24]. Therefore high loaded effluents require additional solutions to conventional biological treatment. Among possible techniques, adsorption on activated alumina is extensively applied, as it is most effective for removing organic compounds such as surfactants, pesticides, dyes, and aromatic molecules [24]. Economic viability of processes using adsorption is thus directly related to their efficiency in regenerating and recycling the activated alumina [25].

A wide spread contamination of shallow ground waters of African has been reported and over $25 \%$ of this water is producing arsenic contaminated water. This is a serious public health concern as the shallow water is the major source of drinking water for almost all of the population [23]. Thousands of people are reported to have already been suffered from arsenicosis and other heavy metal by drinking arsenic contaminated water and millions are at risk of arsenic toxicity due to exposure to arsenic contaminated water. The most important measure needed to combat the arsenic problem is to provide arsenic safe drinking water to the exposed people [25]. Unless suitable alternative drinking water sources are made available, arsenic removal from the shallow water through simple and low cost technologies appears to be an immediate and short-term solution of this problem. In this perspective, an activated alumina is proposed [26]. Activated alumina an effective adsorbent, has been widely proposed in tertiary treatment due to its large specific surface area and pore structure. There have been many researches on activated alumina adsorption 
for organic pollutant removal with the effects of temperature, solution $\mathrm{pH}$, ionic strength, etc. on the adsorption isotherms [20].

Moreover, another important characteristics are the adsorption and regeneration is two processes in which a substance (adsorbate), in gas or liquid phase, accumulates on a solid surface and later regenerated to clean away the adsorbed particle [4]. It is based on the capability of porous materials with large surfaces to selectively retain compounds on the surface of the solid (adsorbent). There are two types of adsorption; physical and chemical adsorptions [27].

\subsection{Physical Adsorption mechanism}

The material have been reported by many research communities for its capability showing physical adsorption and physical adsorption is achieved by Van der Waals forces, dipole interactions, and Hydrogen binding and other ions which give additional priority [15]. There is no electron exchange between adsorbent and adsorbate. Because there is no activation energy required for physical adsorption, the time needed to reach equilibrium is very short. Physical adsorption is a non-specific and a reversible process and allow regenration[16]. The Fig. 1, show the composite indicating high intensity by activated aluminium

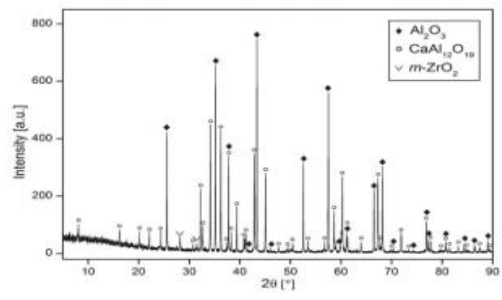

(a)

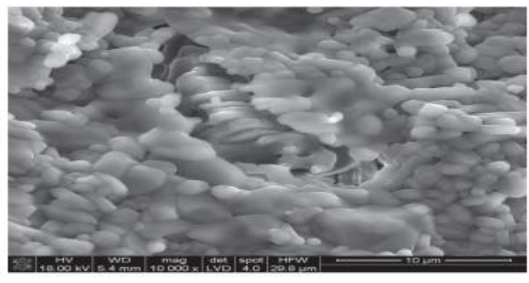

(b)

Fig. 1. (a) The $\mathrm{XRD}$ pattern of the $\mathrm{Al}_{2} \mathrm{O}_{3}-\mathrm{CaAl}_{12} \mathrm{O}_{19}-\mathrm{ZrO}_{2}$ ceramic composite material (b) SEM photomicrograph of the fractured section of the $\mathrm{Al}_{2} \mathrm{O}_{3}-\mathrm{CaAl}_{12} \mathrm{O}_{19}-\mathrm{ZrO}_{2}$ ceramic composite material fabricated with homemade method [16].

As can be observed Fig. 2 shown below an indicate the existence of chemical adsorption results from the chemical link between adsorbent and adsorbate molecule, therefore it is specific as well as irreversible and chemical as well as electronic properties of adsorbent are changed. Binding between adsorbent and adsorbate by covalent bond is called weak chemical adsorption, and that by ionic bonds is called strong chemical adsorption this typical example hydrogen radical for phenol [17].

\subsection{Chemical Adsorption mechanism}

Several researches have reported on chemical mechanism, according [17] the alumina chemical reaction capacity is found to be between $3 \mathrm{mg} / \mathrm{g}$ in alkaline water and $20 \mathrm{mgF} / \mathrm{g}$ in acidic water. At pH 7 in their study, they equally claimed that, the de fluoridation capacity was found to be $5.6 \mathrm{mg} / \mathrm{g}$. The capacity decreases with increased bicarbonate concentration but is found to be independent of the presence of other anions like chloride and sulphate [19]. The saturated medium could be regenerated by $2 \%$ hydrochloric acid, $2 \%$ sodium hydroxide or $1 \%$ sulphuric acid. The fluoride removal obeyed Langmuir's adsorption isotherm indicating that the forces of adsorption are governed by chime-sorption. According to AFP group technologies the chemical mechanism is directly related to surface phenomena (These phenomena are surface reactions, which control the reaction rate. This 
is the reason why specific surface area is an important feature for designing adsorbents in dehydration and other applications) as shown in table 1. Moreover, due to the afore mentioned phenomena the activated alumina have a high adsorption capacity at low partial pressures. Adsorption capacity decreases with increasing temperatures.

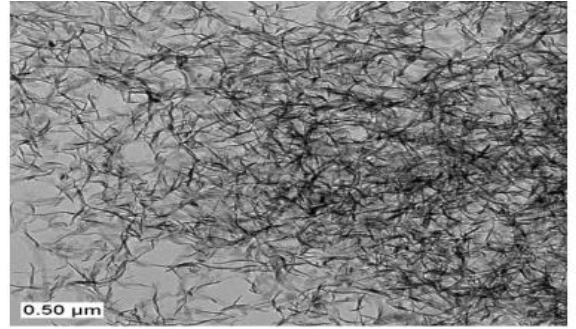

(a)

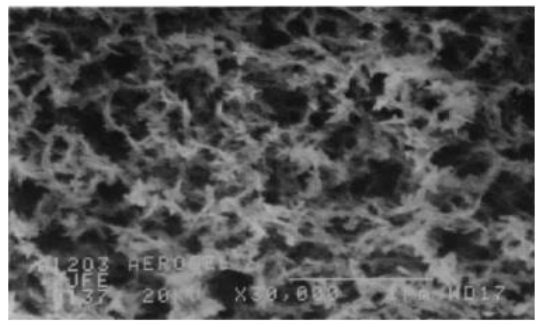

(b)

Fig. 2. (a) TEM image branch like structure (b) SEM showing high porosity [12].

The adsorption process of pollutants by activated alumina includes the following four steps, its begin with transport of absorbates from the bulk fluid to the fluid-solid interface external surface of adsorbent particle, the material have shown capabilities and potentials for treatment industrial product and is equally employed in water and water related applications, like wise it used in gas absorptions etc. This step is also called film diffusion because of the passing through the stationary film of the surrounding of activated alumina before reaching the external surface treatment industrial product and is equally employed in water and water related applications, like wise it used in gas absorptions [26]. Moreover, intra particle transport of absorbates into the activated alumina particle, also called pore diffusion. Where, the adsorptions of absorbates at interior sites of the activated alumina particle and desorption of absorbates from interior sites and transport into the bulk fluid. The specific surface area is another important property that determines adsorbent usage and its capacity which shown in treatment industrial product and is equally employed in water and water related applications, like wise it used in gas absorptions [28]. The total surface area of activated alumina, ranging from 500 to $2000 \mathrm{~m} 2$. g-1, quantifies adsorption sites for molecules to attach treatment industrial product and is equally employed in water and water related applications, like wise it used in gas absorptions [29]. Mesopores, macropores and the nonporous surface of sample represent the external surface. Despite most of the adsorption takes place in the micropores, the meso- and macropores play also an important role in any adsorption process because they serve as passage for the adsorbate to reach micropores.

\section{Preparation and Characteristic of Alumina}

Alumina preparation was proposed by many researchers and especially; the Nano sized gamma alumina the material was proposed [30]. Their approach solely depend on precipitation by aluminium nitrate and sodium carbonate, it was very simple reaction where reaction between aluminium nitrate and sodium carbonate precipitation was done [31-35]. Their results showed that a stable gamma alumina can be prepared in high yield and with high specific surface area with controlled $\mathrm{pH} 8.5$ value, $70^{\circ} \mathrm{C}$ reaction temperature. Their study equally proposed the aging process at $70^{\circ} \mathrm{C}$ temperature. Eliassi and Ranjbar 2014 [25-36] proposed the impurities removal to remove the impurities by washing and then centrifuging rather than using filter paper Fig. 3 shows the gamma alumina calcinated in 
500, (a) SEM image for Nano gamma alumina produced by calcinations in $550^{\circ} \mathrm{C}$ and (b) the XRD Nano gamma alumina produced by calcinations in $550^{\circ} \mathrm{C}$ [37-40].

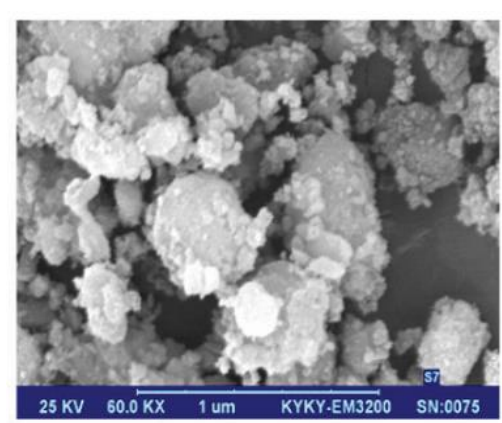

(a)

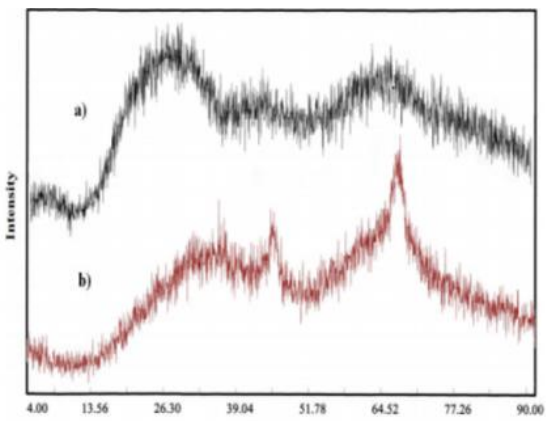

(b)

Fig. 3. (a) gamma alumina calcinated in 500 , (b) nano gamma alumina produced by calcinations in $550^{\circ} \mathrm{C}[14]$.

Similar study was conducted by [25] which stated that they used Sol-gel transition with the aid of pyrolysis of the alumina-based gels prepared via alumatrane precursor. According to [16] the alumina gels were prepared by the sol-gel method via alumatrane precursor the materials were synthesised directly from the reaction of readily available and inexpensive compounds, the compound include aluminium hydroxide and triisopropanolamine were mixed in careful and in a step wise manner. With controlled Sol-gel process parameters, these include time gel time, $\mathrm{pH}$, and temperature and hydrolysis ratio. Bussarin and his team were able to monitor the sol-gel transition of alcoholic alumatrane solution via multiple waveform rheological measurements to characterize the materials [37-40].

\section{Conclusions}

The study summarized the recent development in synthesis and characterization of the activated alumina. The recent techniques in both electrochemical and anodization process employed in synthesizing activated. Different sizes such as Nano sized gamma alumina preparation were equally reviewed. Very good results were observed and summarized various optimum conditions for preparing activated alumina leading to high yield and high specific surface area were summarized, this included degree of $\mathrm{pH}$, reaction temperature etc. The systematic characterization based on SEM, TEM, FTIR, X-ray diffraction and EDX were equally summarized.

\section{References}

1. Ahmed S., Rasul M.G., Martens W.N., Brown R., Hashib M.A., Desalination 261, 318 (2010)

2. Musmarra D., D. Karatza, A. Lancia, M. Prisciandaro, G.M. di Celso, Chem. Eng. Trans. 32, 547-552 (2013)

3. Anirudhan T., S. Sreekumari, J. Environ. Sci. 23, 1989-1998

4. Guo Y., E. Du, Energy Procedia 17, 444-449 (2012)

5. Salvador F., N. Martin-Sanchez, R. Sanchez-Hernandez, M.J. Sanchez-Montero, C. Izquierdo, Microporous Mesoporous Mater. 202, 259-276 (2015) 
6. F. Salvador, N. Martin-Sanchez, R. Sanchez-Hernandez, M.J. Sanchez-Montero, Microporous Mesoporous Mater. 202, 277-296 (2015)

7. P.-J. Lu, H.-C. Lin, W.-T. Yu, J.-M. Chern, J. Taiwan Inst. Chem. Eng. 42 305-311 (2011)

8. Ahmed S., Rasul M.G., Brownb R., Hashib M.A., Journal of Environmental Management 92, 311-330. (2011)

9. Beker U., Ganbold B., Dertli H., Duranog D., Gulbayir 1. Energy Conversion and Management 51, 235-240 (2010)

10. Cadoret L, Rossignol C, Dexpert-Ghys J, et al. Materials Science and Engineering BAdvanced Functional Solid- State Materials 170 (1-3), 41-50 (2010)

11. Darko S. A., Maxwell E., Park S. Thin Solid Films 519 (1). 174-177 (2010)

12. Lam S-M., Sin J-C., Mohamed A-R.. Korean J. Chem. Eng. 27(4), 1109-1116 (2010)

13. Saka, C. Journal of Analytical and Applied Pyrolysis 95, 21-24 (2012)

14. Shah, I. K., Pre, P. \& Alappat, B., Journal of the Taiwan Institute of Chemical Engineers 45, 1733-1738 (2014)

15. Xin-hui, Chemical Engineering and Processing: Process Intensification 53, 53- 62 (2012)

16. Barakat, M.,. New trends in removing heavy metals from industrial wastewater. Arabian Journal of Chemistry 4, 361-377 (2011)

17. Berenguer, R. et al., ScienceDirect 48, 2010, 2734-2745.

18. Eliassi A M. Ranjbar, Int. J. Nanosci. Nanotechnol. 10(1), 13-26 (2014)

19. Bussarin Ksapabutr, Erdogan Gulari, Sujitra Wongkasemjit, Colloids and Surfaces A: Physicochem. Eng. Aspects 233, 145-153 (2004)

20. Michael A. Karakassides, Dimitrios Gournis, Athanasios B. Bourlinos, Pantelis N. Trikalitis and Thomas BakascMagneti, J. Mater. Chem. 13, 871-876 (2016)

21. Ramana Reddy P., Ajith K. M. and N. K. Udayashankar, Adv. Mater. Lett. 7(5), 398401 (2016)

22. Poco J .F. J. H. Satcher Jr. L. W. Hrubesh, Journal of nano-crystaline solids 285, 57$63(2001)$

23. Karthikeyan G, B. V. Apparao, S Meenakshi, 2nd international workshop on fluorosis prevention and defluoridation of water, 79-82 (2014)

24. Abdul Rashid, J. I., Abdullah, J., Yusof, N. A., Hajian, R., Abdul Rashid, J. I., Abdullah, J., ... Hajian, R. The Development of Silicon Nanowire as Sensing Material and Its Applications. Journal of Nanomaterials, 1-16 (2013)

25. Ahmed, R. A., Fekry, A. M. International Journal of Electrochemical Science 8(5), 6692-6708 (2013)

26. Boken, J., Kumar, D. Nanoparticles 4(4), 303-308 (2014)

27. Chen, K. I., Li, B. R., Chen, Y. T. Nano Today. Elsevier Ltd. https://doi.org/10.1016/j.nantod.2011.02.001 (2011)

28. Chua, J. H., Chee, R. E., Agarwal, A., She, M. W., Zhang, G. J. Analytical Chemistry 81(15), 6266-6271(2009)

29. Cui, L., Wu, J., Ju, H. Electrochemical sensing of heavy metal ions with inorganic, organic and bio-materials. Biosensors and Bioelectronics 63, 276-286 (2015)

30. Cui, Y., Wei, Q., Park, H., \& Lieber, C. Science 293 (5533), 1289-1292 (2001)

31. Cui, Y., Zhong, Z., Wang, D., Wang, W. U., Lieber, C. M. Nano Letters 3(2), 149$152(2003)$

32. Dhahi, T. S., Hashim, U., Ahmed, N. M. Science of Advanced Materials 3(2), 233238 (2011)

33. Dielacher, B. K. A Combined Electrical, Plasmonic and Fluidic Measurement System for Metal Nanostructure based Ion Sensing, 22493 (2015) 
34. Eshkeiti, A., Narakathu, B. B., Reddy, A. S. G., Rebrosova, E., Rebros, M., Joyce, M., Atashbar, M. Z. Nano chemistry, 0-3 (2012)

35. Guo, Z., Seol, M., Gao, C., Kim, M., Ahn, J., Choi, Y., Huang, X. Electrochimica Acta 211, 998-1005 (2016)

36. Harrison, B. S. Applications of Nanotechnology. In Principles of Regenerative Medicine (pp. 554-561). https://doi.org/10.1016/B978-012369410-2.50033-4 (2008)

37. Joyner, J. J., V., D. K. International Journal Of Science \& Technoledge 3(4), 80-90 (2015)

38. Korent Urek, Š., Frančič, N., Turel, M., Lobnik, A. Journal of Nanomaterials, https://doi.org/10.1155/2013/501320 (2013)

39. Li, Z., Chen, J., Guo, H., Fan, X., Wen, Z., Yeh, M. H., ... Wang, Z. L. Adv Mater, 2983-2991(2016)

40. Long, F., Zhu, A., \& Shi, H. Sensors 13(10), 13928-13948 (2013) 